\title{
Physicians' Perceptions of Electronic Prescribing with Electronic Medical Records in Kuwaiti Primary Healthcare Centres
}

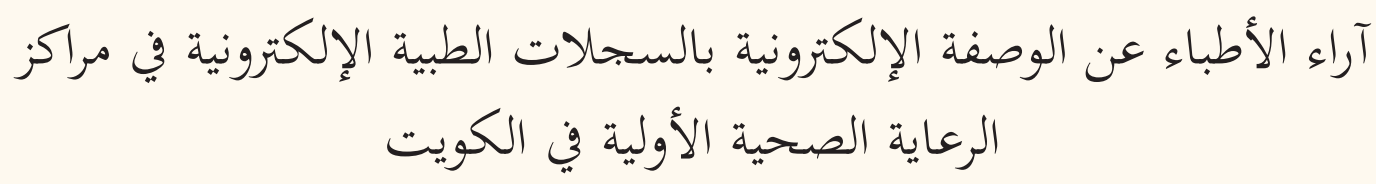

بشاير عبدله المطيري، هنري بوتس، سعدون فارس العازمي

ABSTRACT: Objectives: This study aimed to evaluate physicians' perceptions of electronic prescribing in Kuwaiti primary healthcare centres. Methods: This cross-sectional study was conducted between June and August 2017 among 368 physicians from 25 primary healthcare centres in Kuwait. Data were collected from the participants using a selfreported questionnaire, including sociodemographic characteristics, previous experience with computers and awareness, knowledge and use of e-prescribing systems and their functional features. In addition, perceptions of the benefits and levels of satisfaction associated with e-prescribing were explored. Results: A total of 306 physicians completed the survey (response rate: 83\%). The majority had positive perceptions regarding the use of e-prescribing, particularly in terms of time-savings (86\%), healthcare quality (84\%), productivity $(80 \%)$ and clinical workflow and efficiency (83\%). However, many respondents indicated that e-prescribing systems required additional improvements in terms of functionality. Conclusion: Most physicians in primary healthcare centres in Kuwait recognised the importance of e-prescribing to improve the quality of patient care, streamline workflow, increase productivity and reduce medical errors. However, there is a need to improve the design and infrastructure of e-prescribing systems, which may aid in the adoption of such systems in Kuwait.

Keywords: Computer-Assisted Drug Therapies; Electronic Prescribing; Electronic Medical Records; Physicians; Primary Healthcare; Kuwait.

الملخص: الههف: هدفت هذه الدراسة إلى تقييم آراء الأطباء حول تقديم الوصفات إلكترونياً في مراكز الرعاية الصحية الأولية في الكويت.

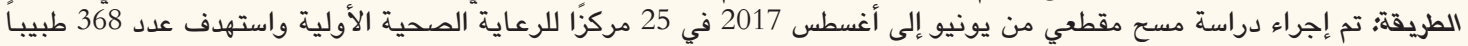

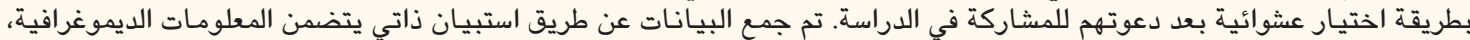

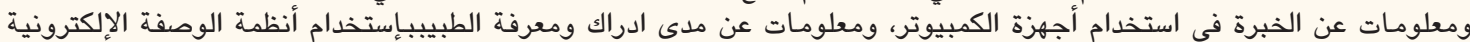

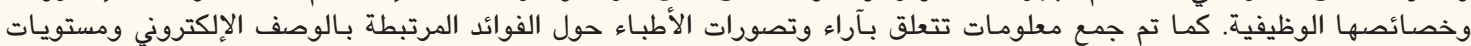

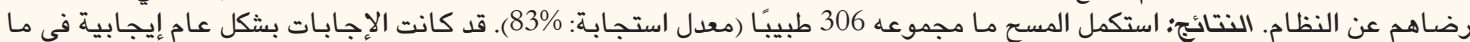

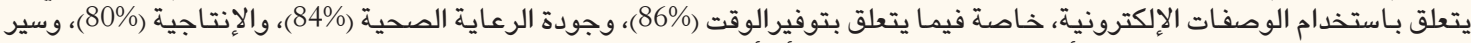

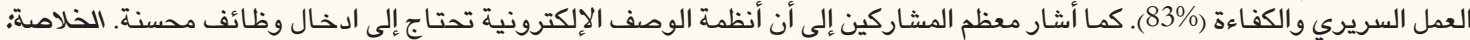



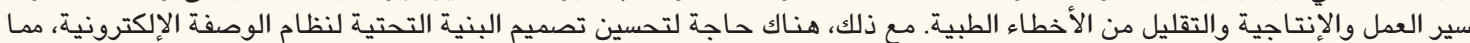
سيسهم في إعتمـادهـا بفعالية في الكويت.

الكلمات المفتاحية: العلاجات الدوائية المدعومة بالحاسوب؛ الوصفة الكترونية؛ السجلات الصحية الإلكترونية؛ الأطباء؛ الرعاية الصحية الأولية؛ الكويت.

\section{AdVANCES IN KNOWLEDGE}

This study found that physicians in Kuwait were generally accepting of the introduction of electronic prescribing as part of an electronic medical record system, recognising the value and potential of such systems to improve efficiency, reduce medical errors and improve patient safety.

However, physicians in Kuwait identified several deficiencies in the implemented e-prescribing systems.

\section{application to Patient Care}

There is a need to address identified deficiencies in e-prescribing systems being implemented in Kuwait in order to optimise the quality of care provided to patients and reduce the potential for prescription errors. 
$\mathrm{P}$ RESCRIBING MEDICINES IS AN IMPORTANT part of public healthcare services; as such, systems that optimise the prescription process are essential. ${ }^{1}$ Electronic prescribing is defined as a computerbased method of creating, transferring, sorting and documenting prescriptions electronically. ${ }^{2}$ A successful e-prescribing system functions as an interoperational platform between physicians and pharmacies to facilitate the exchange of treatment information. ${ }^{3}$ E-prescribing systems often form part of a larger electronic medical record (EMR) system allowing physicians access to a broad range of patient information, including medical histories and details of diagnoses and treatment, in addition to prescription information. ${ }^{4}$

Prescription errors are a common yet avoidable cause of increased morbidity and mortality. ${ }^{5-7}$ Although the implementation of new technologies may initially be challenging, adopting e-prescribing systems can help to reduce the frequency of medication errors, thereby enhancing patient safety and the overall quality of treatment, particularly in primary care settings and for patients with long-term drug regimens. ${ }^{8-10}$ The successful adoption of e-prescribing systems has been reported in many regions worldwide, including the USA, UK, European Union and Canada. ${ }^{10,11}$ The main barriers to implementation include cost, time, lack of efficiency, negative perceptions of technology and its impact on care, lack of prior experience with computers, low computer literacy, limitations in interoperability, difficulty of data entry/ correction and the ability of the system to complete desired tasks. ${ }^{11-15}$ Furthermore, there may be concerns regarding differences in healthcare policies and the enforcement of local privacy and data protection laws. ${ }^{16}$ According to Sicotte et al., preferred style of information acquisition, successful integration of e-prescribing into day-to-day practice and previous computer experience all contribute to a better understanding of technology and can positively influence the usage and adoption of e-prescribing systems. ${ }^{17}$

In Kuwait, healthcare services are offered at the primary, secondary and tertiary level via health centres, regional general hospitals and specialty hospitals. There are a total of 97 primary healthcare centres located throughout the country. ${ }^{18}$ Each residential area has at least one primary healthcare centre, with some centres also incorporating specialised clinics catering to patients with diabetes, dermatological and ophthalmological problems and those requiring antenatal care, among others. Although these centres operate on an independent basis, they are overseen by the Central Directorate of Primary Healthcare in the Kuwaiti Ministry of Health $(\mathrm{MOH}){ }^{18,19}$ In 2000, a national health information EMR system was developed by the $\mathrm{MOH}$ and subsequently implemented in all primary healthcare centres in 2001. The EMR system was specifically designed to support end-users (i.e. physicians, nurses and pharmacists) by providing access to a complete and accurate database of relevant patient information. ${ }^{20}$ This study aimed to evaluate physicians' perceptions of e-prescribing in Kuwaiti primary healthcare centres.

\section{Methods}

This cross-sectional study was conducted between June and August 2017 in 25 primary healthcare centres in Kuwait. The required sample size for the study was based on a finite population of 1,685 physicians. As a conservative estimate, it was assumed that $50 \%$ of users would be satisfied with the current e-prescribing system. Taking into account a $4.6 \%$ error, the number of participants was calculated to be 350 at a 95\% confidence level. Adjusting for a $5 \%$ non-response rate, a total of 368 Kuwaiti physicians were selected by a two-stage stratified random sampling method, considering the proportional allocation of the total population in the study area. In the first stage, a total of 25 primary healthcare centres were randomly selected, comprising five centres from each of the five main regions of Kuwait (Ahmadi, Asmimah, Farwaniya, Hawalli and Jahra). Subsequently, during the second stage, physicians from each of the selected centres were randomly chosen and invited to participate in the survey.

A two-part English-language questionnaire was developed to elicit information from the participants. The first section focused on sociodemographic factors and computer experience (13 items), while the second consisted of 48 items to determine the physicians' perceptions of e-prescribing in four categories: knowledge (four items), functionality (18 items), benefits (18 items) and satisfaction (eight items). All of the questions were closed-ended and were scored on a three-point Likert scale, with one indicating disagreement with the item, two neither agreement nor disagreement and three agreement. A pilot study of 10 physicians who were not included in the final study pre-tested the questionnaire to ensure the clarity and relevance of the items. The questionnaires were physically distributed to the selected physicians during their work shifts and collected one week later by the same researcher.

Data were analysed using the Statistical Package for the Social Sciences (SPSS), Version 24.0 (IBM Corp., Armonk, New York, USA). Responses for each item in the second section of the questionnaire were averaged over the total number of items in the category. As the scores for each dimension were not normally distributed, the results were expressed as minimums, maximums, medians and interquartile ranges (IQRs), with an overall unweighted or weighted score. Mann-Whitney U, 
Table 1: Sociodemographic characteristics of physicians in primary healthcare centres in Kuwait $(\mathrm{N}=306)$

\begin{tabular}{|c|c|}
\hline Characteristic & n (\%) \\
\hline \multicolumn{2}{|l|}{ Age in years } \\
\hline $20-29$ & $23(8)$ \\
\hline $30-39$ & $149(49)$ \\
\hline $40-49$ & $68(22)$ \\
\hline $50-59$ & $44(14)$ \\
\hline$>60$ & $22(7)$ \\
\hline \multicolumn{2}{|l|}{ Gender } \\
\hline Male & $124(41)$ \\
\hline Female & $182(59)$ \\
\hline \multicolumn{2}{|l|}{ Marital status } \\
\hline Single & $50(16)$ \\
\hline Married & $256(84)$ \\
\hline \multicolumn{2}{|l|}{ Education level } \\
\hline Bachelor's degree & $129(42)$ \\
\hline Postgraduate degree & $177(58)$ \\
\hline \multicolumn{2}{|l|}{ Location of medical education } \\
\hline Kuwait & $89(29)$ \\
\hline Abroad & $217(71)$ \\
\hline \multicolumn{2}{|c|}{ Previous work experience in years } \\
\hline$<6$ & $64(21)$ \\
\hline $6-11$ & $123(40)$ \\
\hline $12-17$ & $46(15)$ \\
\hline $18-23$ & $38(12)$ \\
\hline$>24$ & $35(11)$ \\
\hline \multicolumn{2}{|c|}{ Prior computer training at medical school } \\
\hline Yes & $186(61)$ \\
\hline No & $120(39)$ \\
\hline \multicolumn{2}{|l|}{ Level of computer literacy } \\
\hline Basic & $98(32)$ \\
\hline Average & $172(56)$ \\
\hline Excellent & $36(12)$ \\
\hline \multicolumn{2}{|c|}{ Awareness of e-prescribing modules } \\
\hline Yes & $287(94)$ \\
\hline No & $19(6)$ \\
\hline \multicolumn{2}{|l|}{ Use of e-prescribing modules } \\
\hline Yes & $291(95)$ \\
\hline No & $15(5)$ \\
\hline \multicolumn{2}{|c|}{ Awareness of how to use e-prescribing modules } \\
\hline Yes & $288(94)$ \\
\hline No & $18(6)$ \\
\hline \multicolumn{2}{|c|}{ Previous experience using e-prescribing modules in years } \\
\hline Median (interquartile range) & $7(5-11)$ \\
\hline Range & $1-17$ \\
\hline \multicolumn{2}{|c|}{ Number of prescriptions per day } \\
\hline Median (interquartile range) & $42(36-47)$ \\
\hline Range & $15-54$ \\
\hline
\end{tabular}

Table 2: Dimension scores for a survey assessing perceptions of electronic prescribing systems among physicians in primary healthcare centres in Kuwait $(\mathrm{N}=306)$

\begin{tabular}{lcrcc} 
Dimension & \multicolumn{2}{c}{ Unweighted score } & \multicolumn{2}{c}{ Weighted score } \\
& Range & Med (IQR) & Range & Med (IQR) \\
Knowledge & $4-12$ & $12(11-12)$ & $1-3$ & $3(2.8-3)$ \\
Functionality & $18-54$ & $42(37-48)$ & $1-3$ & $2.3(2.1-2.7)$ \\
Benefits & $18-54$ & $49(43-53)$ & $1-3$ & $2.7(2.4-2.9)$ \\
Satisfaction & $8-24$ & $20(19-21)$ & $1-3$ & $2.5(2.4-2.6)$
\end{tabular}

Med $=$ median $; Q R=$ interquartile range .

Kruskal-Wallis and Spearman's rank correlation tests were used to calculate associations at a $5 \%$ significance level.

The study was approved by the Standing Committee for the Coordination of Medical \& Health Research at the Kuwaiti MOH (\#537/2017). All participants were informed of the study's purpose, the anonymity of their data and that participation was voluntary in nature. Written consent was obtained from all participants prior to their inclusion in the study.

\section{Results}

A total of 306 participants took part in the survey (response rate: $83 \%)$. Most respondents were female (59\%), 30-39 years old (49\%), married (84\%), had a postgraduate degree (58\%) and had worked for between 6-11 years (40\%). The majority $(71 \%)$ had received their medical education outside of Kuwait and 61\% had taken computer courses during medical school. More than half (56\%) reported having average computer literacy. Awareness of e-prescribing systems was high (94\%), with 94\% indicating that they understood how to use the system. The vast majority (95\%) were currently using an e-prescribing system, with between 1-17 years of previous experience (median: 7 years; IQR: 5-11 years). The number of daily prescriptions was between 15-54 prescriptions (median: 42 prescriptions; IQR: $36-47$ prescriptions) [Table 1]. The overall weighted median score for the knowledge dimension of the questionnaire was 3 , while the median score for functionality was 2.3. Median weighted scores for the benefits and satisfaction dimensions were 2.7 and 2.5, respectively [Table 2].

Generally, the majority of physicians had positive perceptions regarding the concept of e-prescribing, reporting that the EMR system was easy to use (85\%), efficient $(88 \%)$ and provided easy access to prescriptions services (81\%). Notable benefits of e-prescribing were time-savings (86\%), increased healthcare quality (84\%), productivity (80\%) and clinical workflow and efficiency (83\%). However, many of the respondents indicated that e-prescribing systems should have better functionality, 
Table 3: Perceptions of electronic prescribing systems among physicians in primary healthcare centres in Kuwait $(\mathrm{N}=306)$

\section{Item}

\section{Knowledge}

The EMR e-prescribing system is easy to use

It is easy to access e-prescription services and prescribe medications with this system

I use the EMR e-prescribing system efficiently for most prescriptions

The EMR e-prescribing system clearly displays patient demographic information

Functionality

The EMR e-prescribing system allows me to create new prescriptions

The EMR e-prescribing system allows me to detect prescribing errors

The EMR e-prescribing system allows me to receive medication interaction alerts

The EMR e-prescribing system allows me to receive medication allergy alerts

The EMR e-prescribing system allows me to review patient medication histories

The EMR e-prescribing system allows me to track health maintenance items

The EMR e-prescribing system allows me to select medications

The EMR e-prescribing system allows me to view current medications

The EMR e-prescribing system allows me to add an electronic signature

The EMR e-prescribing system allows me to obtain medication information

The EMR e-prescribing system allows me to review medication reference information

The EMR e-prescribing system allows me to prescribe medication safely

The EMR e-prescribing system allows me to request repeat medications

The EMR e-prescribing system allows me to review formula information

The EMR e-prescribing system allows me to print patient information sheets

The EMR e-prescribing system allows me to print medical information sheets

The EMR e-prescribing system allows me to perform dosing calculations

The EMR e-prescribing system allows me to search by medication name

Benefits

The EMR e-prescribing system helps to control patient medication lists

The EMR e-prescribing system leads to increased prescription accuracy

The EMR e-prescribing system helps to streamline workflow and increase efficiency

The EMR e-prescribing system contributes to financial savings

The EMR e-prescribing system improves communication with pharmacists

The EMR e-prescribing system improves communication with patients

The EMR e-prescribing system leads to greater patient satisfaction

The EMR e-prescribing system results in better security and confidentiality

The EMR e-prescribing system results in better protection of the patient's privacy

The EMR e-prescribing system leads to greater patient safety

The EMR e-prescribing system contributes to time-savings

The EMR e-prescribing system reduces medication errors

The EMR e-prescribing system leads to greater efficiency in physician practice

The EMR e-prescribing system contributes to higher-quality healthcare

The EMR e-prescribing system leads to greater productivity

The EMR e-prescribing system improves flexibility without much mental effort

The EMR e-prescribing system results in faster task accomplishment

The EMR e-prescribing system allows me to treat more patients

Satisfaction

The EMR e-prescribing system is useful for my job

The EMR e-prescribing system makes my job easier

The EMR e-prescribing system is not time-consuming

The EMR e-prescribing system improves the speed and efficiency of processing orders

The EMR e-prescribing system maintains data accuracy

The EMR e-prescribing system makes my job much more difficult

I require more training to use the EMR e-prescribing system

An on-staff support technician is needed to maintain and resolve technical problems

\section{Disagree}

n (\%)

Neither

8 (3)

37 (12)

46 (15)

12 (4)

10 (3)

28 (9)

23 (8)

80 (26)

48 (16)

45 (15)

77 (25)

74 (24)

162 (53)

44 (14)

41 (13)

15 (5)

44 (14)

13 (4)

20 (7)

174 (57)

34 (11)

39 (13)

98 (32)

28 (9)

34 (11)

55 (18)

66 (22)

70 (23)

81 (26)

64 (21)

68 (22)

35 (11)

44 (14)

73 (24)

37 (12)

39 (13)

68 (22)

62 (20)

66 (22)

84 (27)

35 (11)

77 (25)

50 (16)

69 (23)

97 (32)

77 (25)

68 (22)

76 (25)

31 (10)

79 (26)

67 (22)

43 (14)

46 (15)

95 (31)

45 (15)

68 (22)

Agree

261 (85)

248 (81)

268 (88)

203 (66)

213 (70)

155 (51)

100 (33)

231 (75)

252 (82)

164 (54)

265 (87)

252 (82)

77 (25)

151 (49)

135 (44)

145 (47)

190 (62)

146 (48)

223 (73)

226 (74)

90 (29)

230 (75)

172 (56)

160 (52)

254 (83)

200 (65)

224 (73)

200 (65)

187 (61)

213 (70)

217 (71)

206 (67)

262 (86)

199 (65)

223 (73)

256 (84)

246 (80)

186 (61)

242 (79)

217 (71)

21 (7)

7 (2)

$13(4)$

286 (93)

9 (3)

18 (6)

279 (91)

46 (15)

48 (16)

212 (69)

12 (4)

41 (13)

253 (83)

39 (13)

257 (84)

214 (70)

45 (15)

47 (15)

92 (30)

91 (30)

123 (40)

59 (19)

68 (22)

$E M R=$ electronic medical record . 
Table 4: Dimension scores for a survey assessing perceptions of electronic prescribing systems among physicians in primary healthcare centres in Kuwait according to sociodemographic characteristics $(\mathrm{N}=306)$

\begin{tabular}{|c|c|c|c|c|}
\hline \multirow[t]{2}{*}{ Characteristic } & \multicolumn{4}{|c|}{ Median score (IQR) } \\
\hline & Knowledge & Functionality & Benefits & Satisfaction \\
\hline \multicolumn{5}{|l|}{ Gender } \\
\hline Male & $3(2.8-3)$ & $2.3(2.1-2.7)$ & $2.7(2.4-2.9)$ & $2.5(2.3-2.8)$ \\
\hline Female & $3(2.5-3)$ & $2.3(2.1-2.6)$ & $2.8(2.4-2.9)$ & $2.5(2.4-2.6)$ \\
\hline \multicolumn{5}{|l|}{ Marital status } \\
\hline Single & $2.8(2.5-3)$ & $2.4(2.1-2.6)$ & $2.7(2.4-2.9)$ & $2.5(2.3-2.6)$ \\
\hline Married & $3(2.8-3)$ & $2.3(2.1-2.7)$ & $2.7(2.4-2.9)$ & $2.5(2.4-2.6)$ \\
\hline \multicolumn{5}{|l|}{ Education level } \\
\hline Bachelor's degree & $3(2.8-3)$ & $2.4(2.1-2.8)$ & $2.7(2.4-2.9)$ & $2.5(2.4-2.6)$ \\
\hline Postgraduate degree & $3(2.5-3)$ & $2.3(2.1-2.6)$ & $2.7(2.4-2.9)$ & $2.5(2.4-2.6)$ \\
\hline \multicolumn{5}{|c|}{ Location of medical education } \\
\hline Kuwait & $3(2.8-3)$ & $2.2(2-2.5)$ & $2.7(2.3-2.9)$ & $2.5(2.3-2.6)$ \\
\hline Abroad & $2.8(2.5-3)$ & $2.4(2.1-2.7)$ & $2.7(2.4-2.9)$ & $2.5(2.4-2.6)$ \\
\hline \multicolumn{5}{|c|}{ Prior computer training at medical school } \\
\hline Yes & $3(2.8-3)$ & $2.4(2.1-2.7)$ & $2.8(2.4-2.9)$ & $2.5(2.4-2.6)$ \\
\hline No & $2.8(2.5-3)$ & $2.3(2.1-2.6)$ & $2.7(2.3-2.9)$ & $2.5(2.3-2.6)$ \\
\hline \multicolumn{5}{|c|}{ Awareness of e-prescribing modules } \\
\hline Yes & $3(2.8-3)$ & $2.4(2.1-2.7)$ & $2.7(2.4-2.9)$ & $2.5(2.4-2.6)$ \\
\hline No & $2.8(2.5-3)$ & $2.1(1.6-2.6)$ & $2.4(2.1-3)$ & $2.5(2.2-2.7)$ \\
\hline \multicolumn{5}{|c|}{ Use of e-prescribing modules } \\
\hline Yes & $3(2.8-3)$ & $2.4(2.1-2.7)$ & $2.7(2.4-2.9)$ & $2.5(2.4-2.6)$ \\
\hline No & $2.8(2-3)$ & $2.1(1.8-2.6)$ & $2.6(2.1-3)$ & $2.4(2-2.5)$ \\
\hline \multicolumn{5}{|c|}{ Awareness of how to use e-prescribing modules } \\
\hline Yes & $3(2.8-3)$ & $2.4(2.1-2.7)$ & $2.7(2.4-2.9)$ & $2.5(2.4-2.6)$ \\
\hline No & $2.8(2.5-3)$ & $2(1.5-2.6)$ & $2.4(2.2-2.9)$ & $2.4(2.3-2.6)$ \\
\hline
\end{tabular}

$I Q R=$ interquartile range.

Table 5: Relationship between sociodemographic variables and dimension scores for a survey assessing perceptions of electronic prescribing systems among physicians in primary healthcare centres in Kuwait $(\mathrm{N}=306)$

\begin{tabular}{|c|c|c|c|c|c|c|c|c|}
\hline \multirow{2}{*}{ Variable } & \multicolumn{2}{|c|}{ Knowledge } & \multicolumn{2}{|c|}{ Functionality } & \multicolumn{2}{|c|}{ Benefits } & \multicolumn{2}{|c|}{ Satisfaction } \\
\hline & $\begin{array}{c}\mathrm{R} / \mathrm{Z} \\
\text { score }\end{array}$ & $P$ value & $\begin{array}{c}\mathrm{R} / \mathrm{Z} \\
\text { score }\end{array}$ & $P$ value & $\begin{array}{c}\mathrm{R} / \mathrm{Z} \\
\text { score }\end{array}$ & $P$ value & $\begin{array}{c}\mathrm{R} / \mathrm{Z} \\
\text { score }\end{array}$ & $P$ value \\
\hline Age & $-0.041^{*}$ & 0.474 & $0.102^{*}$ & 0.075 & $0.000^{*}$ & 0.999 & $-0.104^{*}$ & 0.068 \\
\hline Gender & $0.170^{*}$ & 0.865 & $0.461^{\dagger}$ & 0.645 & $0.408^{\dagger}$ & 0.683 & $0.596^{\dagger}$ & 0.551 \\
\hline Marital status & $1.142^{\dagger}$ & 0.253 & $0.635^{\dagger}$ & 0.525 & $0.722^{\dagger}$ & 0.470 & $1.088^{\dagger}$ & 0.277 \\
\hline Education level & $0.092^{\dagger}$ & 0.927 & $1.524^{\dagger}$ & 0.128 & $0.066^{\dagger}$ & 0.947 & $0.820^{\dagger}$ & 0.412 \\
\hline Location of medical education & $1.205^{\dagger}$ & 0.228 & $2.434^{\dagger}$ & 0.015 & $1.473^{\dagger}$ & 0.141 & $0.168^{\dagger}$ & 0.866 \\
\hline Prior computer training at medical school & $0.958^{\dagger}$ & 0.338 & $1.546^{\dagger}$ & 0.122 & $2.223^{\dagger}$ & 0.026 & $0.998^{\dagger}$ & 0.318 \\
\hline Computer literacy & $0.050^{*}$ & 0.387 & $0.015^{*}$ & 0.797 & $0.071^{*}$ & 0.214 & $0.011^{*}$ & 0.849 \\
\hline Awareness of e-prescribing modules & $1.726^{\dagger}$ & 0.084 & $2.069^{\dagger}$ & 0.039 & $1.123^{\dagger}$ & 0.258 & $0.359^{\dagger}$ & 0.720 \\
\hline Use of e-prescribing modules & $2.386^{\dagger}$ & 0.017 & $1.792^{\dagger}$ & 0.073 & $0.859^{\dagger}$ & 0.391 & $2.066^{\dagger}$ & 0.039 \\
\hline Awareness of how to use e-prescribing modules & $1.932^{\dagger}$ & 0.053 & $2.656^{\dagger}$ & 0.008 & $1.269^{\dagger}$ & 0.204 & $0.887^{\dagger}$ & 0.375 \\
\hline Previous experience using e-prescribing modules & $-0.003^{*}$ & 0.958 & $0.005^{*}$ & 0.353 & $-0.005^{*}$ & 0.937 & $0.070^{*}$ & 0.219 \\
\hline Number of prescriptions per day & $0.028^{*}$ & 0.629 & $0.091^{*}$ & 0.112 & $-0.016^{*}$ & 0.718 & $-0.049^{*}$ & 0.396 \\
\hline
\end{tabular}

$I Q R=$ interquartile range; EMR = electronic medical record. "Using Spearman's rank correlation coefficient. ${ }^{\dagger}$ Using a Mann-Whitney U test. 
Table 6: Spearman's rank correlations between dimensions in a survey assessing perceptions of electronic prescribing systems among physicians in primary healthcare centres in Kuwait $(\mathrm{N}=306)$

\begin{tabular}{lccccccc} 
Dimension & \multicolumn{2}{c}{ Knowledge } & \multicolumn{2}{c}{ Functionality } & \multicolumn{2}{c}{ Benefits } \\
& R & $\boldsymbol{P}$ & R & $\boldsymbol{P}$ & R & $\begin{array}{c}\boldsymbol{P} \\
\text { value }\end{array}$ \\
Functionality & 0.326 & $<0.001$ & - & - & - & - \\
Benefits & 0.350 & $<0.001$ & 0.538 & $<0.001$ & - & - \\
Satisfaction & 0.177 & 0.001 & 0.241 & $<0.001$ & 0.254 & $<0.001$
\end{tabular}

for instance regarding the ability to add electronic signatures (57\%), receive medication interaction alerts (53\%) and perform dosing calculations (47\%). Respondents also highlighted the need for technical support (58\%) [Table 3].

Tables 4 and 5 show the relationship between the overall median scores in each of the questionnaire dimensions and selected sociodemographic characteristics. The median functionality score of physicians who had received medical education abroad was significantly higher than that of those who had been educated in Kuwait (2.4 versus 2.2; $P=0.015$ ). Physicians who had received computer courses at medical school had a significantly higher median benefits score compared to those who did not (2.8 versus $2.7 ; P=0.026$ ). Median functionality scores were also significantly higher among physicians who were aware of e-prescription systems (2.4 versus $2.1 ; P=0.039$ ) and who understood how to use them (2.4 versus $2 ; P=0.008)$. Median scores for the satisfaction and knowledge dimensions varied according to use of e-prescribing systems; users had significantly higher satisfaction ( 2.5 versus $2.4 ; P=0.039$ ) and knowledge ( 3 versus $2.8 ; P=0.017$ ) scores compared to nonusers. All four dimensions of the questionnaire were significantly related with each other $(P \leq 0.001)$, with Spearman's rank correlation coefficients ranging from 0.177-0.350 [Table 6].

\section{Discussion}

The current study assessed perceptions of e-prescribing among physicians in primary healthcare centres in Kuwait. As physicians are the primary end-users of such systems, they are in the best position to identify factors that affect successful adoption and implementation of the system. ${ }^{21}$ The majority of physicians in the present study had positive perceptions of e-prescribing, particularly with regards to time-savings, ease of use, accessibility and increased healthcare quality, productivity and efficiency. In particular, most physicians anticipated that e-prescribing would result in improvements in prescription accuracy, data confidentiality and patient satisfaction and help to reduce prescription errors.
The findings of the present study are in line with those of previous research. In a study in Singapore, Tan et al. reported that most doctors were satisfied with specific functions of e-prescribing systems such as the ability to review prescription histories, receive drug interaction alerts and create prescriptions and e-prescription processing and system speed..$^{22}$ A Swedish study noted that physicians were satisfied with the clear display of patient information on such systems. ${ }^{23}$ Thomas et al. found that physicians using an ambulatory e-prescribing system in the USA were optimistic about improved workflow, efficiency, cost-savings and patient communication. ${ }^{24}$ Other studies have also reported perceived improvements in patient safety, care quality, efficiency, productivity and communication with pharmacies. ${ }^{1,9-11,23,25,26}$

Despite mostly positive perceptions, more than half of the physicians in the current study indicated that e-prescribing systems should have better functionality, such as the ability to add electronic signatures, receive medication interaction alerts and perform dosing calculations. Cohen et al. highlighted a desire for e-prescribing technology to incorporate electronic signatures among physicians in South Africa, while Savage et al. revealed similar issues regarding allergy and interaction alerts and dosing calculations among staff at a district general hospital in the UK. ${ }^{27,28}$ In addition, a major area of concern in the present study was ensuring adequate technical support in the workplace for system maintenance and to overcome technical problems. These results are consistent with the findings of other studies regarding the need for greater technical and organisational support for the successful implementation and maintenance of e-prescribing systems. ${ }^{1,3}$ Jawhari et al. also emphasised the need for on-site technical support. ${ }^{29}$

The main limitation of the current study was that the sample was not representative of all primary healthcare physicians in Kuwait; furthermore, as the questionnaire data were self-reported, the findings may be subject to bias.

\section{Conclusion}

This study found that physicians' perceptions of e-prescribing systems in Kuwaiti primary healthcare centres were mostly positive, particularly with regards to improvements in time-savings, efficiency, quality of patient care and safety. These results support the continued adoption and use of e-prescribing systems in Kuwait. However, several deficiencies were identified regarding the functionality of e-prescribing systems and the lack of technical support and maintenance. Improvements in these areas may maximise the effective adoption and use of such systems. 


\section{ACKNOWLEDGEMENTS}

The authors would like to thank all of the physicians who participated in this study as well as the directors of the primary healthcare centres for facilitating and supporting the data collection process.

\section{CONFLICT OF INTEREST}

The authors declare no conflicts of interest.

\section{FUNDING}

No funding was received for this study.

\section{References}

1. Gagnon MP, Nsangou ÉR, Payne-Gagnon J, Grenier S, Sicotte C. Barriers and facilitators to implementing electronic prescription: A systematic review of user groups' perceptions. J Am Med Inform Assoc 2014; 21:535-41. https://doi.org/10.1136/ amiajnl-2013-002203.

2. eHealth Initiative Foundation. A clinician's guide to electronic prescribing. From: www.citizenshealthinitiative.org/sites/citize nshealthinitiative.org/files/media/Reports/Clinicians_Guide_ to_e-Prescribing_Final_100708.pdf Accessed: Sep 2018.

3. Grossman JM, Cross DA, Boukus ER, Cohen GR. Transmitting and processing electronic prescriptions: Experiences of physician practices and pharmacies. J Am Med Inform Assoc 2012; 19:353-9. https://doi.org/10.1136/amiajnl-2011-000515.

4. Abramson EL, Barrón Y, Quaresimo J, Kaushal R. Electronic prescribing within an electronic health record reduces ambulatory prescribing errors. Jt Comm J Qual Patient Saf 2011; 37:470-8. https://doi.org/10.1016/S1553-7250(11)37060-2.

5. Cresswell K, Coleman I, Slee A, Williams R, Sheikh A. Investigating and learning lessons from early experiences of implementing ePrescribing systems into NHS hospitals: A questionnaire study. PLoS One 2013; 8:e53369. https://doi.org/10.1371/jour nal.pone.0053369.

6. Pirmohamed M, James S, Meakin S, Green C, Scott AK, Walley TJ, et al. Adverse drug reactions as cause of admission to hospital: Prospective analysis of 18820 patients. BMJ 2004; 329:15-19. https://doi.org/10.1136/bmj.329.7456.15.

7. Schneeweiss S, Göttler M, Hasford J, Swoboda W, Hippius M, Hoffmann AK, et al. First results from an intensified monitoring system to estimate drug related hospital admissions. Br J Clin Pharmacol 2001; 52:196-200. https://doi.org/10.1046/j.03065251.2001.01425.x

8. Eslami S, Abu-Hanna A, de Keizer NF. Evaluation of outpatient computerized physician medication order entry systems: A systematic review. J Am Med Inform Assoc 2007; 14:400-6. https://doi.org/10.1197/jamia.M2238.

9. Grossman JM, Gerland A, Reed MC, Fahlman C. Physicians' experiences using commercial e-prescribing systems. Health Aff (Millwood) 2007; 26:w393-404. https://doi.org/10.1377/hlt haff.26.3.w393.

10. Salmon JW, Jiang R. E-prescribing: History, issues, and potentials. Online J Public Health Inform 2012; 4:4304. https://doi.org/ 10.5210/ojphi.v4i3.4304.

11. Samadbeik M, Ahmadi M, Sadoughi F, Garavand A. A comparative review of electronic prescription systems: Lessons learned from developed countries. J Res Pharm Pract 2017; 6:3-11. https://doi.org/10.4103/2279-042X.200993.

12. Van Der Meijden MJ, Tange HJ, Troost J, Hasman A. Determinants of success of inpatient clinical information systems: A literature review. J Am Med Inform Assoc 2003; 10:235-43. https://doi.org/10.1197/jamia.M1094.
13. Aarts J, Doorewaard H, Berg M. Understanding implementation: The case of a computerized physician order entry system in a large Dutch university medical center. J Am Med Inform Assoc 2004; 11:207-16. https://doi.org/10.1197/jamia.M1372.

14. Al-Azmi SF, Al-Enezi N, Chowdhury RI. Users' attitudes to an electronic medical record system and its correlates: A multivariate analysis. Health Inf Manag 2009; 38:33-40. https://doi. org/10.1177/183335830903800205.

15. Ammenwerth E, Mansmann U, Iller C, Eichstädter R. Factors affecting and affected by user acceptance of computer-based nursing documentation: Results of a two-year study. J Am Med Inform Assoc 2003; 10:69-84. https://doi.org/10.1197/jamia. M1118.

16. Greenberg MD, Ridgely MS, Bell DS. Electronic prescribing and HIPAA privacy regulation. Inquiry 2004-2005; 41:461-8. https://doi.org/10.5034/inquiryjrnl_41.4.461.

17. Sicotte C, Taylor L, Tamblyn R. Predicting the use of electronic prescribing among early adopters in primary care. Can Fam Physician 2013; 59:e312-21.

18. Regional Health Systems Observatory, World Health Organization. Health system profile: Kuwait. From: apps.who.int/ medicinedocs/documents/s17297e/s17297e.pdf Accessed: Sep 2018 .

19. Buabbas A. Investigation of the adoption of telemedicine technology in the Kuwaiti health system: Strategy and policy of implementation for overseas referral patients. PhD thesis, 2013, Brunel University, London, UK.

20. Akbar AA. Patient information system for national health care: An intranet internet-based model for the State of Kuwait. PhD thesis, 2003, University of Leeds, Leeds, UK.

21. Tamblyn R, Huang A, Kawasumi Y, Bartlett G, Grad R, Jacques A, et al. The development and evaluation of an integrated electronic prescribing and drug management system for primary care. J Am Med Inform Assoc 2006; 13:148-59. https://doi.org/10.1 197/jamia.M1887.

22. Tan WS, Phang JS, Tan LK. Evaluating user satisfaction with an electronic prescription system in a primary care group. Ann Acad Med Singapore 2009; 38:494-7.

23. Hellström L, Waern K, Montelius E, Astrand B, Rydberg T, Petersson G. Physicians' attitudes towards ePrescribing: Evaluation of a Swedish full-scale implementation. BMC Med Inform Decis Mak 2009; 9:37. https://doi.org/10.1186/1472-6947-9-37.

24. Thomas CP, Kim M, McDonald A, Kreiner P, Kelleher SJ Jr, Blackman MB, et al. Prescribers' expectations and barriers to electronic prescribing of controlled substances. J Am Med Inform Assoc 2011; 19:375-81. https://doi.org/10.1136/ami ajnl-2011-000209.

25. Johnson KB, Lehmann CU; Council on Clinical Information Technology of the American Academy of Pediatrics. Electronic prescribing in pediatrics: Toward safer and more effective medication management. Pediatrics 2013; 131: e1350-6. https://doi. org/10.1542/peds.2013-0193.

26. Abramson EL, Patel V, Pfoh ER, Kaushal R. How physician perspectives on e-prescribing evolve over time: A case study following the transition between EHRs in an outpatient clinic. Appl Clin Inform 2016; 7:994-1006. https://doi.org/10.4338/ ACI-2016-04-RA-0069.

27. Cohen JF, Bancilhon JM, Jones M. South African physicians' acceptance of e-prescribing technology: An empirical test of a modified UTAUT model. S Afr Comput J 2013; 50:43-54. https://doi.org/10.18489/sacj.v50i1.175.

28. Savage I, Cornford T, Klecun E, Barber N, Clifford S, Franklin BD. Medication errors with electronic prescribing (eP): Two views of the same picture. BMC Health Serv Res 2010; 10:135. https:// doi.org/10.1186/1472-6963-10-135.

29. Jawhari B, Keenan L, Zakus D, Ludwick D, Isaac A, Saleh A, et al. Barriers and facilitators to electronic medical record (EMR) use in an urban slum. Int J Med Inform 2016; 94:246-54. https://doi.org/10.1016/j.ijmedinf.2016.07.015. 